\title{
Anxiety indicators for women in the postpartum period
}

\author{
V. Sudraba ${ }^{1}$ and L. Zemite $^{2}$ \\ ${ }^{1}$ Rīga Stradiňš University, Riga, Latvia \\ ${ }^{2}$ Riga Maternity Hospital, Riga, Latvia
}

\begin{abstract}
Situations, which are dangerous and sad, provoke state anxiety (S-anxiety), but trait anxiety (T-anxiety) shows anxiety like person's acquired behavioural disposition. The aim was to evaluate postpartum anxiety indicators of women that have had the vaginal birth and women that have had surgery in Riga regional medical institutions that provide obstetric services. Respondents - 100 women (50 - with vaginal birth; 50 with caesarean section surgery) were surveyed by 2 instruments: the demographic survey and the state - trait anxiety inventory, STAI Form Y-1 (Spielberger et al., 1983), adapted in Latvian by Škuškovnika (2004). The results reflect the statistical difference between State anxiety indicators (Sanxiety) of women that have had the vaginal birth $(M=35.38 ; \mathrm{SD}=9.98)$ and women that have had the surgery $(M=37.20$; $\mathrm{SD}=9.41)$ was not found $(p=0.304)$. Indicators of Trait anxiety (T-anxiety) show that there was not statistically significant $(p=0.059)$ difference between women that have had the vaginal birth $(M=36.92 ; \mathrm{SD}=7.81)$ and women that have had the surgery $(M=39.24$; $\mathrm{SD}=7.56)$, however, it should be noted that the average anxiety scores were higher after surgery.
\end{abstract}

\section{Introduction}

Time from the birth of a child until the first year after the birth is a critical period to develop affective disorders [1]. Immediately after the childbirth the mother experiences stress due to the lack of energy caused by new responsibilities [2]. While pregnancy is like a defender against panic attacks, depression and development of anxiety, postpartum period increases their risk. During this period the inclination to the development of anxiety increases because demands to a woman grow, and she often has to face lack of sleep [3].

As aggravating factors which promote development of anxiety and postpartum depression are mentioned a history of mental illness, smoking, low socio-economic status, relationship or marriage problems, single mothers, loss of a previous child, lack of knowledge in the care of a new-born $[2,4,5]$. At the same time married women or physically fit women had a lower degree of anxiety [6].

Postpartum anxiety is stated to be one of the most common psychotic disorders in Canada [7]. In Israel about $13 \%$ of women suffer from symptoms of depression in postpartum period [3]. In Georgia anxiety in the postpartum period is found in $17-20 \%$ cases [8], but in Greece it ranges from 6.1 to $27.9 \%$ in the postpartum period [1]. In the study [9] in Germany prevalence of postpartum anxiety was found in $11.1 \%$ cases but in 
$18.4 \%$ of anxiety cases depressive disorders were diagnosed. Studies [6] show that $1.5 \%$ of puerperal women can develop any mental disorder (mood disorders, anxiety, tendency to alcoholism, etc.).

Comparing to vaginal birth, Caesarean section surgery is related to a higher risk of complications, longer recovery period, lower satisfaction and greater risk of postpartum mood disorders. Depressed mood was more often observed in women who had unplanned Caesarean section surgery. Study results show that women, who give birth themselves, control the process and outcome, have a reduced possibility to postpartum mood disorders and an increased feeling of satisfaction [10].

Postpartum depression is a widely studied subject, however, there is no sufficient attention given to panic and anxiety studies in the postpartum period, although they are often faced on a daily basis [3].

Spielberger (1985a), as mentioned [11] distinguishes two anxiety aspects: (1) state anxiety (S-anxiety) - it is characterized by subjective, deliberate perception of threat and tension which are connected with activation and irritation of autonomic nervous system. Situations which are considered to be dangerous and threatening provoke this state in a human. (2) Anxiety as a personality trait (trait anxiety/T-anxiety) - means motive or acquired behavioural disposition which encourages an individual to perceive broad, objectively safe object range as containing threat and encourages to react to them.

It was assumed that $\mathrm{T}$-anxiety could be measured in real time and that it changes over time, indicating to what extent an individual perceives the environment as dangerous or threatening. S-anxiety is defined as anxiety differences between individuals; it means differences in tendency to perceive stress situations as dangerous or threatening reacting to them with more or less explicit situational anxiety changes [11]. Average indicators of Sanxiety in women from Latvia [11] in reproductive age group 19-39 are 38.34, but for age group $40-49$ it is 36.74 , while for T-anxiety it is accordingly 43.00 and 40.73 . If anxiety indicators of a respondent correspond to the average indicators in appropriate age group it is predictable that an individual mostly is able to assess the situation adequately and react accordingly. If indicators exceed the average indicators of a particular age group there are possible rapid changes in mood, tears, and nervousness about expected difficulties not concentrating on the current situation, too long and non-effective analyzing of own mistakes as well as insecurity, uneasiness and disbelief in themselves [11].

The goal of this work was to state the differences of anxiety indicators (S-anxiety and T-anxiety) between women that have had vaginal birth and women that have had the surgery.

\section{Materials and methods}

\subsection{Object of study}

Research data were collected during the time period from 31.03.2016 to 01.05.2016. In total 100 respondents took part in the research: 50 women who had vaginal birth and 50 women who had Caesarean section surgery. Criteria for participant inclusion in the research: puerperal women 2-4 days after labor with a child born alive and able to fill in questionnaires independently (in Latvian). The research was done obtaining permission from Riga Stradiṇš University Ethics Committee and considering all ethical standards.

\subsection{Study instruments}

Respondents filled in socio-demographic data survey (age, place of residence, education, employment, marital status, the number of previous births, types of birth) and The state - 
trait anxiety inventory, STAI Form Y-1 (Spilberger, Gorsuch, Lushene, Vagg, Jacobs, 1983), which was adapted in Latvian by Škuškovnika [11].

STAI Form Y-1 consists of 40 closed questions which are divided into two sub-groups. First 20 questions (S-anxiety) evaluate current anxiety state asking respondents to describe their feelings at present moment using subjective questions about sadness, tension, nervousness, worry, etc. Next 20 questions (T-anxiety) evaluate stable aspects which are long-lasting - peace, trust and security [12]. Answers are evaluated according to the Likert scale 4 point gradation starting from "no, not at all" ending with "yes, definitely".

\subsection{Statistical analysis}

Data processing was done using SPSS version 20. Statistically processing research data with Kolmogorov-Smirnov test help, it was possible to determine whether obtained data correspond to standard breakdown. Further statistical data processing was done using Mann-Whitney $U$ test.

\section{Results}

100 puerperal women took part in the research -50 women who had vaginal birth and 50 women who had the surgery in the age group 19-43 (see Table 1). It is obvious that the biggest group consists of women in the age group 26-37. Most respondents live in registered relationships, have higher education, are employed and live in a city. Half of respondents had previously given birth.

Table 1. Socio-demographic data of respondents.

\begin{tabular}{|l|c|c|c|c|c|c|}
\hline \multicolumn{2}{|c|}{ Socio-demographic data } & $\begin{array}{c}\text { All } \\
(N=\mathbf{1 0 0})\end{array}$ & \multicolumn{2}{c|}{$\begin{array}{c}\text { Vaginal birth } \\
(\boldsymbol{n}=\mathbf{5 0})\end{array}$} & \multicolumn{2}{c|}{$\begin{array}{c}\text { Caesarean section } \\
\text { surgery }(\boldsymbol{n}=\mathbf{5 0})\end{array}$} \\
\cline { 3 - 7 } & & & $\boldsymbol{n}$ & $\mathbf{\%}$ & $\boldsymbol{n}$ & $\mathbf{\%}$ \\
\hline \multirow{4}{*}{ Age } & $19-25$ & 22 & 14 & 28 & 8 & 16 \\
\cline { 2 - 7 } & $26-31$ & 33 & 17 & 34 & 16 & 32 \\
\cline { 2 - 7 } & $32-37$ & 32 & 14 & 28 & 18 & 36 \\
\cline { 2 - 7 } & $38-43$ & 13 & 5 & 10 & 8 & 16 \\
\hline \multirow{5}{*}{ Family status } & Married & 61 & 30 & 60 & 31 & 62 \\
\cline { 2 - 7 } & Unregistered & 37 & 19 & 38 & 18 & 36 \\
\cline { 2 - 7 } & Live alone & 2 & 1 & 2 & 1 & 2 \\
\hline \multirow{4}{*}{ Education } & University & 67 & 33 & 66 & 34 & 68 \\
\cline { 2 - 7 } & High school & 30 & 15 & 30 & 15 & 30 \\
\cline { 2 - 7 } & Elementary & 3 & 2 & 4 & 1 & 2 \\
\hline \multirow{4}{*}{ Employed } & Yes & 84 & 43 & 86 & 41 & 82 \\
\cline { 2 - 7 } & No & 16 & 7 & 14 & 9 & 18 \\
\hline \multirow{2}{*}{$\begin{array}{l}\text { Place of } \\
\text { residence }\end{array}$} & City & 94 & 48 & 96 & 46 & 92 \\
\hline Previous birth & Country & 6 & 2 & 4 & 4 & 8 \\
\cline { 2 - 7 } & Yes & 50 & 26 & 52 & 24 & 48 \\
\cline { 2 - 7 } & No & 50 & 24 & 48 & 26 & 52 \\
\hline
\end{tabular}

Comparing socio-demographic indicators with state or trait anxiety indicators (see Table $2)$, it is clear that statistically significant differences $(p=0.036)$ appear only in group of women that had the surgery regarding age and trait anxiety. The lowest Trait anxiety indicators were in the age group 26-31. The highest Trait anxiety indicators were in the age 
group 38-43. The rest socio-demographic data between respondent groups regarding anxiety do not differ.

Table 2. Socio-demographic data comparison by groups.

\begin{tabular}{|c|c|c|c|c|}
\hline \multirow{2}{*}{} & \multicolumn{2}{|c|}{$\begin{array}{c}\text { Vaginal birth } \\
(\boldsymbol{n}=\mathbf{5 0})\end{array}$} & \multicolumn{2}{c|}{$\begin{array}{c}\text { Caesarean section surgery } \\
(\boldsymbol{n}=\mathbf{5 0})\end{array}$} \\
\cline { 2 - 5 } & \multicolumn{2}{|c|}{$\mathbf{s i g}$} & \multicolumn{2}{c|}{ sig } \\
\cline { 2 - 5 } & S-anxiety & T-anxiety & S-anxiety & T-anxiety \\
\hline Age & 0.424 & 0.291 & 0.341 & $\mathbf{0 . 0 3 6}$ \\
\hline Family status & 0.115 & 0.058 & 0.603 & 0.167 \\
\hline Education & 0.219 & 0.700 & 0.743 & 0.330 \\
\hline Employed & 0.123 & 0.559 & 0.397 & 0.785 \\
\hline $\begin{array}{c}\text { Place of } \\
\text { residence }\end{array}$ & 0.343 & 0.691 & 0.649 & 0.155 \\
\hline
\end{tabular}

Looking at the indicators of descriptive statistics for women that had vaginal birth (see Table 3) and women that had the surgery (see Table 4), it is clear that both state anxiety and trait anxiety average indicators are bigger for women that had the surgery, although maximum indicators are bigger for women that had vaginal birth. However, comparing data with conclusive statistical method (see Table 5), it is clear that statistically significant differences appear neither in state anxiety indicators $(p=0.304)$ nor in trait anxiety indicators $(p=0.059)$, although close to the significant border.

Table 3. Anxiety indicators of descriptive statistics for women that had vaginal birth $(n=50)$.

\begin{tabular}{|l|l|l|l|l|l|}
\hline & Min & Max & Mean & SD & 95\% CI \\
\hline S-anxiety & 21 & 66 & 35.88 & 9.975 & $33.05-38.71$ \\
\hline T-anxiety & 25 & 58 & 36.92 & 7.809 & $34.70-39.14$ \\
\hline
\end{tabular}

Table 4. Anxiety indicators of descriptive statistics for women that had the surgery $(n=50)$.

\begin{tabular}{|l|l|l|l|l|l|}
\hline & Min & Max & Mean & SD & 95\% CI \\
\hline S-anxiety & 22 & 58 & 37.20 & 9.413 & $34.52-39.88$ \\
\hline T-anxiety & 24 & 55 & 39.24 & 7.561 & $37.09-41.39$ \\
\hline
\end{tabular}

Table 5. Comparison of anxiety indicators by groups.

\begin{tabular}{|c|c|c|c|c|c|}
\hline \multirow{2}{*}{$\begin{array}{l}\text { Kind of } \\
\text { anxiety }\end{array}$} & \multicolumn{2}{|c|}{$\begin{array}{c}\text { Vaginal birth } \\
(\boldsymbol{n}=\mathbf{5 0})\end{array}$} & \multicolumn{2}{c|}{$\begin{array}{c}\text { Caesarean section } \\
\text { surgery }(\boldsymbol{n}=\mathbf{5 0})\end{array}$} & \multirow{2}{*}{$\boldsymbol{p}$} \\
\cline { 2 - 5 } & $\boldsymbol{M}$ & SD & $\boldsymbol{M}$ & SD & \\
\hline S-anxiety & 35.88 & 9.98 & 37.20 & 9.41 & 0.304 \\
\hline T-anxiety & 36.92 & 7.81 & 39.24 & 7.56 & 0.059 \\
\hline
\end{tabular}

\section{Discussion}

Looking at trait anxiety and state anxiety average indicators it is clear that for women who had the surgery they are higher than for women who had vaginal birth, although women who had vaginal birth got more maximum number of points. It was found [13] that using epidural anaesthesia or performing Caesarean section surgery, anxiety indicators were higher than giving birth naturally. 
Comparing with vaginal birth, Caesarean section surgery is connected with higher risk of complications, longer recovery period and higher risk of postpartum mood disorders. Depressed mood was more often observed in women who had unplanned Caesarean section surgery. Study [10] results show that women, who give birth themselves, control the process and outcome, have a reduced possibility to postpartum mood disorders and an increased feeling of satisfaction.

Looking more specifically at trait anxiety indicators and age relationship of women who had the surgery, which is statistically significant, it was observed that the lowest trait anxiety indicators were in the age group 26-31, but the highest trait anxiety indicators were in the age group 38-43. Such result could be related to woman's greater concern for health and bigger responsibility for being able to deal with new-born baby and herself in the postsurgery period.

Looking more specifically at relationship between trait anxiety for women who had vaginal birth and marital status, which is close to critical value, it was observed that in case of registered marriage anxiety indicators were lower than in cases of not registered relationship or non-being in relationship. With reference to the research [4] it was found that single women have a greater risk to face depression and anxiety in the perinatal period.

The research gives general information about the tendency of anxiety indicators in specific respondent group. Such evaluation can be used as a basis for further research of factors affecting anxiety indicators, with the aim to reduce them ultimately and thus providing high-quality care in Latvian medical institutions. Repeated survey would be necessary to improve and specify data.

\section{Conclusions}

Statistically significant difference in anxiety indicators between women who had vaginal birth and women who had the surgery was not found. Although the range between the lowest and the highest anxiety indicators is bigger for women who had vaginal birth, both average state anxiety indicator and average trait anxiety indicator are higher for women who had the surgery. Between demographic data and anxiety indicators for women who had vaginal birth and women who had the surgery statistically significant differences have not been found, except connection between trait anxiety and age for women who had the surgery. As the average anxiety indicators are not too high, it is possible to conclude that the environment in Riga postpartum units corresponds to the required because slightly increased indicators are natural for such an emotional experience as the birth of a child or the surgery.

\section{References}

1. O. Giakoumaki, K. Vasilaki, L. Lili, M. Skouroliakou, G. Liosis. J. Psychosom. Obstet. Gynecol. 30, 21-28 (2008)

2. S. Shrestha, K. Adachi, M.A. Petrini, S. Shrestha. Int. Nurs. Rev. 61, 427-434 (2014)

3. I.S. Polachek, L.H. Harari, M. Baum, R.D. Strous. Isr. J. Psychiatry Relat. Sci. 51, 128-134 (2014)

4. L.E. Sockol, C.N. Epperson, J.P. Barber. Arch. Womens Ment. Health. 17, 199-212 (2014)

5. J. Yelland, G. Sutherland, S.J. Brown. BMC Public Health. 10, 771 (2010) http://www.ncbi.nlm.nih.gov/pmc/articles/PMC3022850/ 
6. V. Sagayadevan, S. Pheng Lee, E. Abdin, J. Vaingankar, H. Chen, S.A. Chong, M. BMC Women's Health. 15, 1-9 (2015)

7. W. Simpson, M. Glazer, N. Michalski, M. Steiner, B.N. Frey. Can. J. Psychiatry. 59, 434-440 (2014)

8. S.L. Farr, P.M. Dietz, M.W. O’Hara, K. Burley, J. Ko. J. Womens Health. 23, 120 128 (2014)

9. C. Reck, K. Struben, M. Backenstrass, U. Stefenelli, K. Reinig, T. Fuchs, C. Sohn, C. Mundt. Acta Psychiatr. Scand. 118, 459-468 (2008)

10. R.S. DeLuca, M. Lobel. Anal. Soc. Issues Public Policy. 14, 183-204 (2014)

11. D. Škuškovnika. Trauksme latviešiem un Latvijā dzīvojošiem krieviem. Promocijas darbs. Rīga: Latvijas Universitāte [In Latvian: Anxiety for Latvian and Russion, who live in Latvia. Dissertation.] (2004)

12. L.J. Julian. Arthritis Care Res. 63, 467-472 (2011)

13. J. Henderson, M. Redshaw. J. Reprod. Infant Psychol. 31, 465-478 (2013) 